\title{
Obituary
}

\section{Memorial for our Editorial Board Member, Kanok Pavusithipaisit}

\section{Patty Christiena Willis*}

Founding International Administrator, eCAM

On June 16, 2005, I received the sad news that Professor Kanok Pavusithipaisit had passed away. He was recommended to the Board by Dr Francesco Marotta, an Editorial Board member from Milano who met Professor Kanok on one of his many travels in Asia and wrote, 'He is a great man as well as professor of Endocrinology \& Reproductive Biology, Director of the Institute of Science \& Technology for Research and Development in Mahidol University, Thailand. The Institute is a powerful one, with strong government links and grants, and high level conferences such as the one I attended on thalassemia where there was much discussion concerning natural compounds potentially useful for RBC haemolysis and iron-deposition, etc. He is currently working on the protective benefits of antioxidant Vitamin E on spermatogenesis after exposure to gamma radiation and the protective powers of curcumin from radiation. So, once again, natural compounds and solid basic science are being combined in a country where the need for inexpensive biotechnological applications is a reality'. After hearing of his death, Dr Marotta described how Dr Kanok gave him his own running shoes so that he could take a morning run on the beach.

As well as his impressive achievements in science, Dr Kanok was a wonderful human being and loved by all those who worked with him. On a trip for $e C A M$ to learn more about traditional medicine in Thailand, I experienced his generosity firsthand in early December of last year. To give you an idea of his gentle character, I include an excerpt of his New Year's message for it shows something of his kind spirit. Right before my visit, he had an accident and broke his arm quite badly. In his message, he wrote of what he had learned from this experience:

(i) Encouragement and friendship are the most precious gifts that are always appreciated.

(ii) Accidents can take place anytime. We have to be careful 'all the time'.

(iii) The disabled are truly admirable as they can cope with hardships although they must suffer bitterness immeasurably.

(iv) The medical profession, including nurses and physical therapists, is an honorable profession. Their helpful hands and will to serve have given 'life' to many patients.

He closed with:

As the New Year is around the corner, let me send you my love and respect to all who are very considerate, kind and helpful. May all of you stay in good health, enjoy life and reap all the good things you have sown.

Dr Kanok's actions reaped many great benefits, as expressed in the letter that announced his death: 'Please share with us the deepest sympathy to his family for the unexpected and insurmountable loss of the great person named Kanok Pavasuthipaisit, who was very gentle, kind and passionate. A man who cared for others more than himself and gave more than he took'.

*E-mail: chprince@land.hokuriku.ne.jp

(C) The Author (2005). Published by Oxford University Press. All rights reserved.

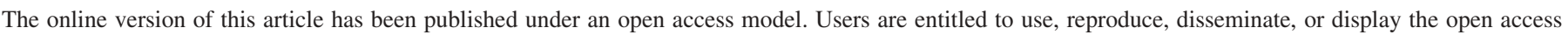

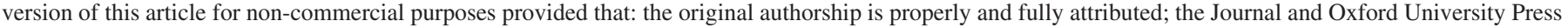

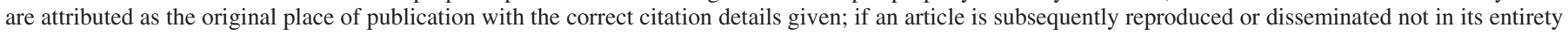
but only in part or as a derivative work this must be clearly indicated. For commercial re-use, please contact journals.permissions@oxfordjournals.org 


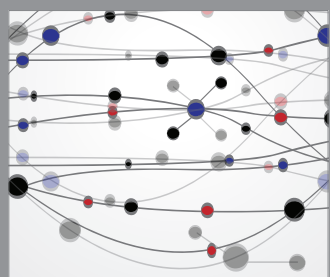

The Scientific World Journal
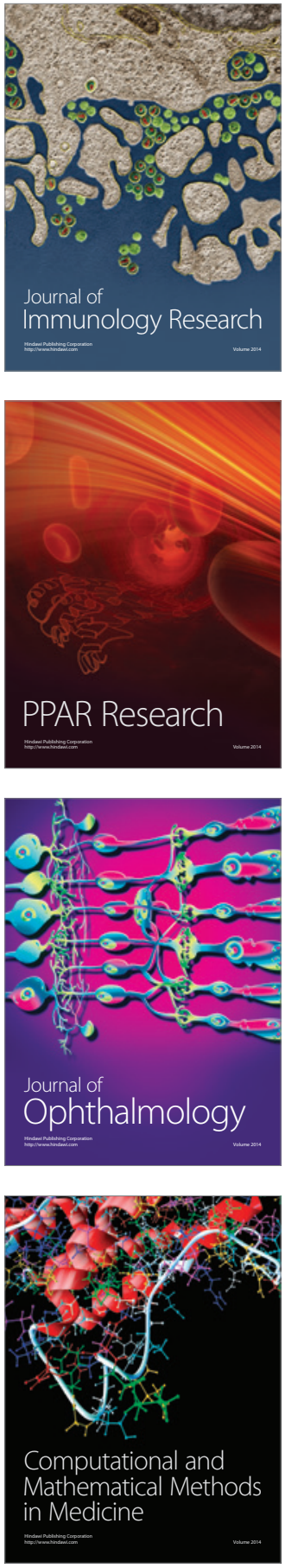

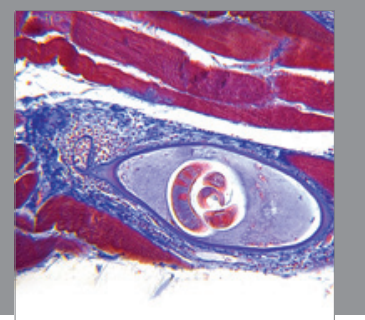

Gastroenterology

Research and Practice
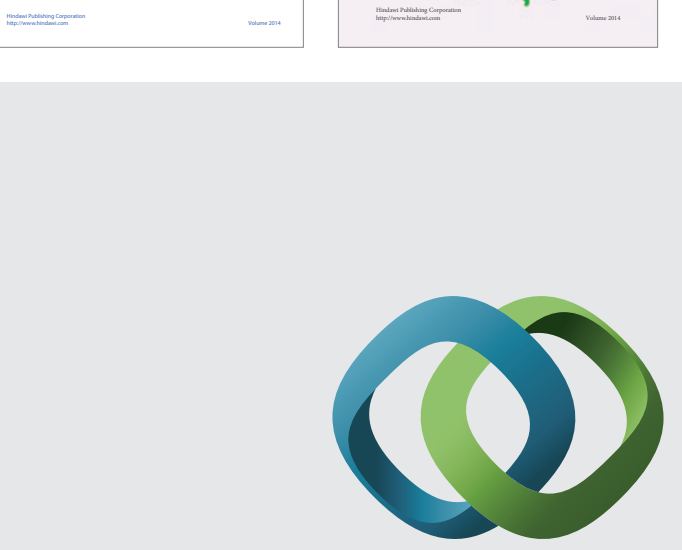

\section{Hindawi}

Submit your manuscripts at

http://www.hindawi.com
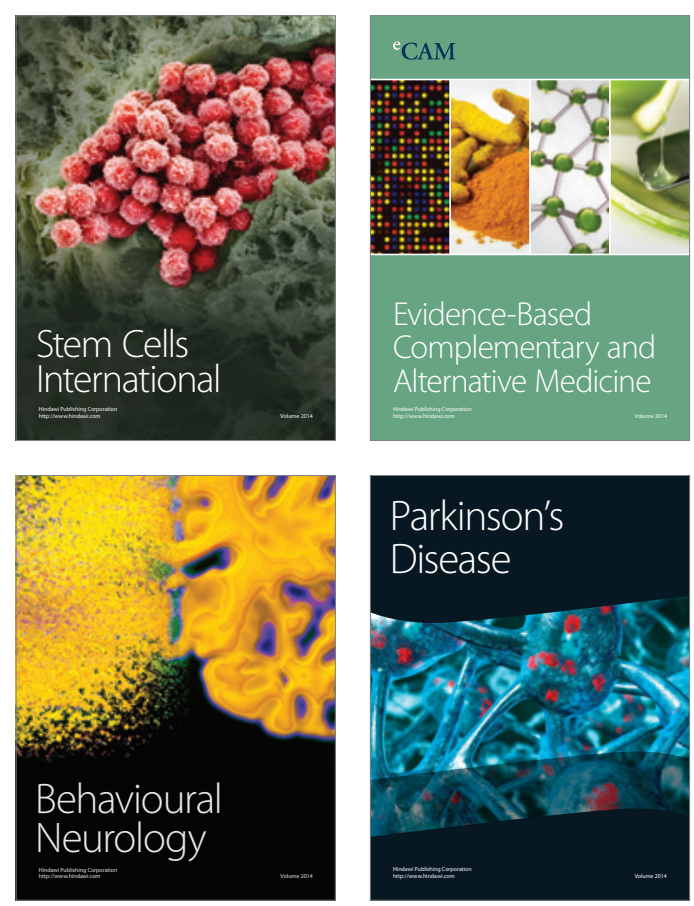

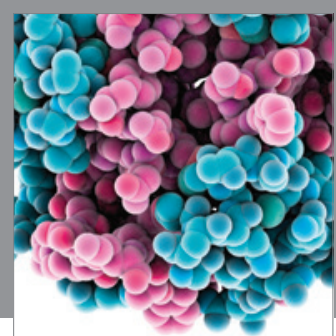

Journal of
Diabetes Research

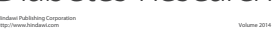

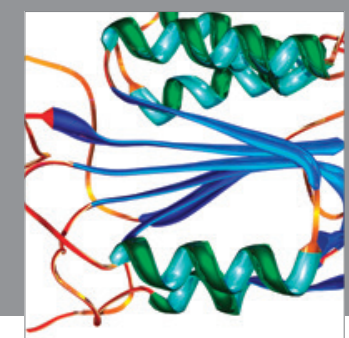

Disease Markers
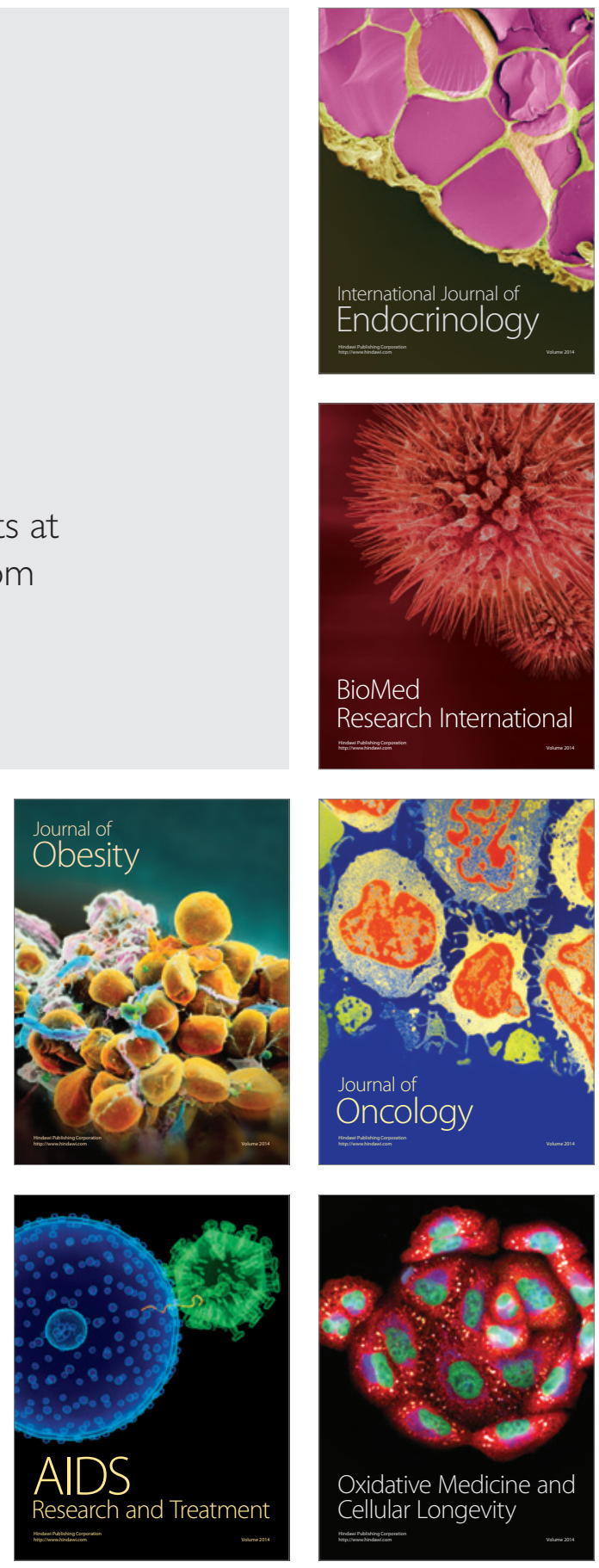